\title{
$\mathrm{PH} 102_{\text {debate }}$
}

a debate Comunicación y redes sociales en instituciones culturales

| coordina Candela González Sánchez

\section{Cultura y redes sociales. Una ventana infinita que necesita profesionalidad}

\author{
Sandra Sancho Ruiz, Claudia Alfonso, Olga Palomares | Lavisible \\ URL de la contribución <www.iaph.es/revistaph/index.php/revistaph/article/view/4801>
}

A la pregunta de si podemos hablar de las redes sociales como nuevas instituciones de la cultura, quizás hasta hoy, habríamos contestado que no. Principalmente, porque las redes sociales no son en sí mismas una institución; son (o eran) una herramienta fantástica para la interacción con los públicos, una manera sencilla de conocerlos mejor, de establecer una relación duradera y de llegar a lugares antes inimaginados. Pero claro, 2020 nos ha puesto sobre la mesa el cambio de paradigma a modo de bofetada. Los procesos de aceleración de la digitalización en 2020, debido a la COVID-19, ponen de manifiesto la importancia de las redes sociales en el ámbito de sociabilidad de las personas. La relevancia actual de ellas ya no tiene punto de discusión y, como espacios digitales de creación, observamos una efervescencia de performance. Las redes sociales son un punto de desarrollo creativo y a la vez, un camino de alienación de las nuevas generaciones. Una ventana infinita.

Desde esa perspectiva, los ámbitos culturales que rescatan la investigación, la conservación y la reflexión deben ampliar sus esfuerzos en las redes sociales, casi con la

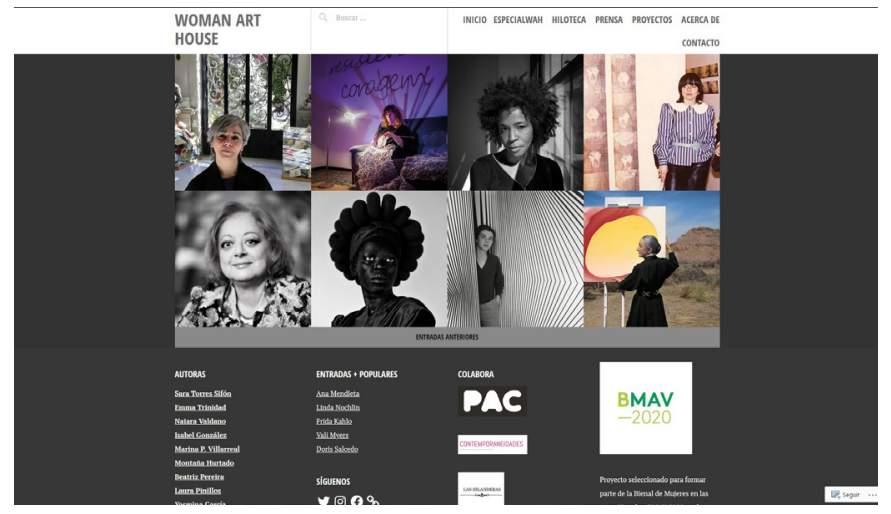

https://womanarthouse.com/ misma relevancia que puede tener el espacio físico. Y como siempre nos pasa al sector, llegamos tarde.

En relación con las estrategias de comunicación que lideran las instituciones culturales, hace ya algunos años que el término "creación de contenidos" se volvió casi un mantra. Desde la experiencia y la observación, las instituciones culturales continúan apostando por tener una mayor presencia en Instagram, con variedad de contenidos y con la creación de otros propios para la red. Más allá de la simple difusión de actividades. Pero son muy pocos los que arriesgan. De cara al futuro cercano se están planteando el comisariado de arte digital y las propuestas de programación online con plataformas totalmente interactivas. Es por ello que se observa una apuesta por la actualización de la web que, desde hace unos años, vuelve a estar en el centro de toda estrategia de comunicación. Por último, cabría destacar el resurgir de las newletter como construcción de relatos casi personalizados. Una manera de generar un diálogo entre institución y público.

¿Encontramos procesos creativos a través de las redes institucionales o son solo nuevas oportunidades de negocio? Cuánto nos cuesta reconocer que de la cultura se debería poder vivir, como de cualquier otro sector. Ahora bien, ¿hemos acostumbrado a los públicos a no pagar por los productos culturales de Internet? Por un lado, ahora estamos viviendo una explosión creativa digital y sus niveles de producción son rápidos y accesibles. Las nuevas generaciones de jóvenes ahora tienen capacidad de editar vídeos, de realizar composiciones, de crear narrativas, etc. Pero también tienen capacidad de rentabilizar su trabajo sin intermediarios. En fin, creemos que una cosa no quita a la otra. Las redes sociales son, como ya hemos dicho, una ventana infinita, pero hay que saber cuál es el objetivo para estar en ellas, qué 


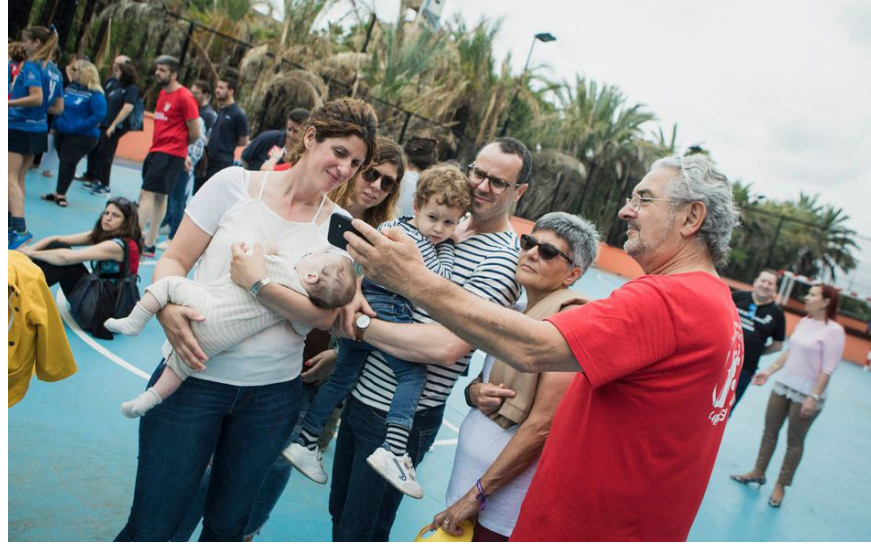

Compartir contenido online, 2018 | foto Raúl Sánchez

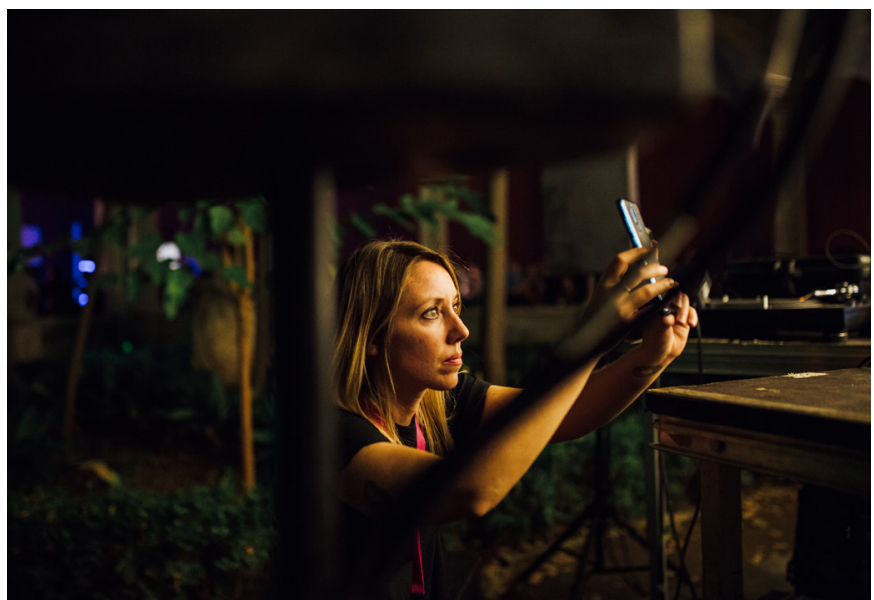

Responsable de comunicación en el Festival Volumens comunicando a través de las redes sociales | foto Abel Gimeno

queremos conseguir y cómo. A eso se le llama estrategia y es necesaria que detrás de ella existan profesionales. Algo que nosotras llevamos mucho tiempo reclamando. Cuando un profesional, que dispone de todas las herramientas necesarias, plantea una estrategia global de comunicación, los resultados son más que visibles. Quizás las redes sociales no nos permiten ver que detrás de una cuenta interesante, de un creador que expone su obra, o una institución que comunica de manera acertada, hay siempre un equipo de trabajo.

En cuanto a cómo es la participación en la cultura mediada por las redes y si podemos hablar de una comunidad cultural digital, aquí las respuestas pueden ser muy generacionales. Quizás con la pandemia se ha reforzado la idea de comunidad cultural digital, pero se debe seguir construyendo puentes que permitan que la experiencia sea enriquecedora. $Y$ ahí hay que diferenciar la experiencia física de la virtual. No podemos ser meros espectadores, y las redes nos ayudan a acercar el debate, a encaminar la cultura hacia la co-creación y por su puesto, a trabajar por la participación. Solo así estaremos sacando el máximo de provecho a las redes sociales.

Para estar siempre actualizadas profesionalmente, revisamos e investigamos las nuevas corrientes artísticas y sus formas de comunicarse. Existen numerosos proyectos culturales y acciones en redes, pero quizás, por destacar algunas, recomendaríamos la cuenta de "Girls From Today", un proyecto totalmente novedoso de Fanzine con contenido actualizado para Instagram, o @WomanArtHouse que desde Twitter reivindica el papel de las mujeres artistas y te permite conocer cosas maravillosas. Y nosotras siempre recomendamos seguir cuentas como la de Artbasel, o MOCO Museum si se quiere estar al tanto de las tendencias más modernas en el arte. 